\title{
"A Randomized Comparison of Sample Adequacy and Diagnostic Yield of EBUS-TBNA using various Suction Pressures"
}

\section{Anant Mohan ( $\sim$ anantmohan@yahoo.com )}

All India Institute of Medical Sciences https://orcid.org/0000-0002-2383-9437

Hariharan lyer

All India Institute of Medical Sciences

Karan Madan

All India Institute of Medical Sciences

Vijay Hadda

All India Institute of Medical Sciences

\section{Saurabh Mittal}

All India Institute of Medical Sciences

\section{Pawan Tiwari}

All India Institute of Medical Sciences

Deepali Jain

All India Institute of Medical Sciences

R M Pandey

All India Institute of Medical Sciences

\section{Avneet Garg}

All India Institute of Medical Sciences

\section{Randeep Guleria}

All India Institute of Medical Sciences

\section{Research Article}

Keywords: EBUS-TBNA, diagnostic yield, sample adequacy, suction

Posted Date: February 5th, 2021

DOI: https://doi.org/10.21203/rs.3.rs-199536/v1

License: (c) (i) This work is licensed under a Creative Commons Attribution 4.0 International License.

Read Full License 


\section{Abstract}

Introduction: The evidence for using vacuum suction during EBUS is sparse, and the optimal suction pressure for obtaining adequate samples is not yet determined.

Objectives: To assess the influence of suction on adequacy and diagnostic yield of EBUS TBNA.

Methods: This single-center, prospective, randomized, non-inferiority trial assessed whether no-suction and $10 \mathrm{ml}$ suction are non-inferior to $20 \mathrm{ml}$ suction for adequacy and diagnostic yield of EBUS-TBNA aspirates.

Results: 323 lymph nodes were sampled using EBUS-TBNA. Baseline characteristics of lymph nodes were comparable in the three suction groups. The overall adequacy of EBUS-TBNA aspirates in the "Nosuction," $10 \mathrm{ml}$, and $20 \mathrm{ml}$ suction was $90 \%, 83.49 \%$, and $77.88 \%$, respectively. The difference in the adequacy was groups $12.12 \%$ (95\% Cl: $3.93-20.3)$ and $5.61 \%(95 \% \mathrm{Cl}$ : $-3.27-14.49)$ for no-suction versus $20 \mathrm{ml}$ and $10 \mathrm{ml}$ versus $20 \mathrm{ml}$ suction, respectively. No-suction and $10 \mathrm{ml}$ were non-inferior to $20 \mathrm{ml}$ suction in terms of sample adequacy. At a superiority margin of 3.92\%, no-suction was superior to $20 \mathrm{ml}$ suction for sample adequacy $(\mathrm{p}<0.05)$. The overall diagnostic yield was comparable $(63.6 \%, 52.3 \%$, and $57.7 \%$ in $0,10 \mathrm{ml}$, and $20 \mathrm{ml}$, respectively; p-not significant). The proportion of aspirates which were predominantly blood was similar (No-suction $-10.9 \%, 10 \mathrm{ml}-13.8 \%, 20 \mathrm{ml}-15.4 \%$; $p=0.62$ )

Conclusions: EBUS-TBNA with or without the application of vacuum suction does not influence specimen adequacy and diagnostic yield. "No-suction" is superior to $20 \mathrm{ml}$ suction pressure and is associated with a lesser risk of bloody samples.

\section{Introduction}

Assessment and sampling of enlarged mediastinal lymph nodes have traditionally been done using flexible bronchoscopy-guided transbronchial needle aspiration (TBNA), CT-guided biopsy or mediastinoscopy. Since the past decade, Endobronchial ultrasound-guided TBNA (EBUS-TBNA) has become an essential investigation in accessing mediastinal structures, providing sample adequacy of 85 to $93 \%,(1,2)$ and a diagnostic yield ranging from 37 to $90 \% .(3,4)$

Several factors are known to influence the yield of EBUS-TBNA, including the needle size,(5) number of passes performed,(6) and nodal size.(4) In clinical practice, EBUS-TBNA is commonly performed by applying vacuum suction, although evidence regarding its utility is inconsistent. $(7,8)$ Consequently, a recent technical Working Group report also suggested that EBUS-TBNA may be performed with or without the application of suction.(9) The likely benefit obtained by using suction should be weighed against the increased possibility of bloody aspirates. Very few studies have performed a systematic comparison of different suction pressures in EBUS, and most of them have focused primarily on lymphadenopathy due to malignant etiology. However, benign disorders such as tuberculosis and sarcoidosis form a significant proportion of referrals for EBUS in several settings. $(7,10)$ 
Given the fact that vacuum suction is considered an essential step in the EBUS procedure, we aimed to determine the optimum suction pressure for both malignant and benign mediastinal lesions by comparing the sample adequacy and diagnostic yield of EBUS- TBNA aspirates using three different suction pressures, i.e., No-suction, $10 \mathrm{ml}$ and $20 \mathrm{ml}$.

\section{Materials And Methods}

This was a prospective, randomized, single-blind, non-inferiority study performed at an academic tertiary level hospital in North India. Adult patients referred for EBUS for undiagnosed hilar or mediastinal lymphadenopathy and having lymph node size more than $0.5 \mathrm{~cm}$ in short axis, as seen on the EBUS ultrasound image, were recruited. Patients with cardiovascular comorbidities such as ischemic heart disease, or uncontrolled hypertension, and subjects with deranged coagulation profile were excluded. Necessary ethical approval was obtained from the local Institution Ethics Committee vide Ref No. IECPG272/07.09.2017 dated 27.10.2017. The trial was registered in Clinical trials registry of India (CTRI 2017/10/010202) and was conducted according to the CONSORT recommendations.(11)

\section{Study Technique}

After obtaining informed written consent, EBUS was performed after under intravenous anesthesia using midazolam and fentanyl. Two percent lignocaine, using 'spray as you go' technique, was used for topical anesthesia. Olympus BF-UC-180F EBUS scope equipped with a linear ultrasound transducer at the tip and dedicated ultrasound image processor (Olympus EU-ME1) was used for all procedures. Lymph nodes greater than $0.5 \mathrm{~cm}$ in the short axis on the EBUS ultrasound vision were sampled. For study purposes, only one lymph node per patient was sampled using a $21 \mathrm{G}$ needle.

Additional lymph nodes, if sampled, were not included for analysis but were used for clinical decisionmaking. The lymph node of interest was randomly allocated into either of the three suction pressures, i.e., No-suction, $10 \mathrm{ml}$, or $20 \mathrm{ml}$, using a random number sequence generated by a staff member who was not an active participant in the study. Three needle punctures were performed into each lymph node with the randomly allocated suction pressure. Material obtained with these three passes was smeared on to a slide to assess adequacy and diagnostic yield. The fixed smears were stained using Papanicolaou stain and evaluated under a microscope by the cytopathologist for sample adequacy.(12) Cell-block and liquidbased cytology were not done routinely for all patients as a protocol in our pathology department. Rapid On-site Evaluation (ROSE) was not used to guide the sampling of the index lymph node. The final diagnosis was given by a dedicated pathologist who was unaware of the amount of suction applied.

The primary outcome measure was the comparison of specimen adequacy between groups, while the secondary outcome measure was diagnostic yield. Adequate sample was defined as those showing presence of lymphocytes or carbon laden macrophages or necrosis or definite diagnostic material (e.g., malignant cells, acid-fast bacilli, necrotizing or non-necrotizing granuloma).(12) ${ }^{12}$ Diagnostic sample was 
defined as the proportion of procedures where specimens demonstrated positivity for tuberculosis (TB) (i.e., presence of acid-fast bacilli or necrotizing granulomas), non-necrotizing granulomas or malignant cells.

Statistical analysis: Sample size was calculated for a three-group parallel non-inferiority trial keeping 20 $\mathrm{ml}$ as control pressure and $10 \mathrm{ml}$ and No-suction as the test groups to compare EBUS-TBNA sample adequacy rate based on the assumption of $80 \%$ adequacy in each of the suction pressure group with a $15 \%$ non-inferiority margin, $95 \%$ confidence level and $80 \%$ power.(13) Based on the above, the number of patients required in each group was 100 . Hence, a minimum of 300 patients was planned to be recruited. Data were managed on an Excel spread sheet. For comparison of baseline characteristics, continuous variables following normal distribution were done by independent t-test (for two groups) and one-way ANOVA (for more than two independent groups) followed by post hoc comparison using the Bonferroni method of $p$-value correction. The association of categorical variables was assessed by Chi-square test/Fisher exact test as appropriate. The difference between various suction pressures in terms of adequacy and diagnostic yield was assessed. All analysis was performed using STATA version 14 TX: StataCorp LP and $p$-value $<0.05$ was taken as statistically significant.

\section{Results}

The study was conducted between September 2017 and February 2019 at a tertiary care teaching hospital in India. The recruitment and evaluation process of the study is depicted in Figure 1.After randomization, the procedure could not be completed in two subjects; hence, these were not included in the final analysis of adequacy and diagnostic yield. The study included 325 patients (60\% males) with mean (standard deviation) age, 46.9 (15.8) years. The baseline characteristics of the study group are depicted in Table 1. Of all subjects, 111 (34.2\%) were randomized in the "No-suction" group, 109 (33.5\%) in $10 \mathrm{ml}$ suction, and $105(32.3 \%)$ in the $20 \mathrm{ml}$ suction group. Table 2 depicts the characteristics of patients in each of the three suction pressure groups.

\section{Lymph node characteristics:}

The lymph node characteristics, i.e., size (short axis), echogenicity, calcification, coagulation necrosis, central hilar structure, presence of intranodal vessels, consistency, and margins were noted in all three groups (Table 3). No difference was observed between the groups with respect to any of the abovementioned nodal characteristics.

\section{Comparison of sample adequacy of EBUS-TBNA aspirates with either of the three suction pressures in all the patients:}

The overall adequacy of EBUS-TBNA aspirates in the "No-suction," $10 \mathrm{ml}$ suction, and $20 \mathrm{ml}$ suction groups was $90 \%, 83.49 \%$, and $77.88 \%$, respectively. The difference in the adequacy between No-suction and $20 \mathrm{ml}$ negative suction was $12.12 \%$ (C.I., 3.93 to 20.3), and between $10 \mathrm{ml}$ suction and $20 \mathrm{ml}$ negative suction was 5.61 \% (C.I., -3.27 to 14.49). No-suction and $10 \mathrm{ml}$ suction were non-inferior to $20 \mathrm{ml}$ 
suction in terms of adequacy of EBUS-TBNA aspirates. (Figure 2) It was observed that "No-suction" was non-inferior to $20 \mathrm{ml}$ suction for sample adequacy, with a difference of 12.12\% (C.I., 3.93 to 20.3). Thus, the $95 \%$ confidence interval of the effect lies not only above our non-inferiority margin but also lies entirely above 0 . It was also seen that at a superiority margin of $3.92 \%$, No-suction pressure was superior to $20 \mathrm{ml}$ suction pressure in terms of sample adequacy $(p<0.05) .{ }^{13}$

The three common diseases which comprised of almost $70 \%$ of our cases were Sarcoidosis, Tuberculosis, and bronchogenic carcinoma (excluding procedures for lung cancer staging). A subgroup analysis comparing the adequacy of EBUS-TBNA in each of the three suction pressures in these diseases was performed and was found to be similar. (Table 4)

Comparison of diagnostic yield of EBUS-TBNA aspirates between the three suction pressures:

The overall diagnostic yield of EBUS-TBNA aspirates in the "No-suction," $10 \mathrm{ml}$ suction, and $20 \mathrm{ml}$ suction groups were $63.6 \%, 52.3 \%$, and $57.7 \%$, respectively. The difference in the diagnostic yield between the three suction pressures was not statistically significant when computed for the entire patient group, or within each of the above disease categories. (Table 5)

\section{Influence of Lymph node characteristics on EBUS sample adequacy:}

In all the three suction groups, there was no association between sample adequacy and lymph node characteristics. Similarly, the mean size (short axis) of the lymph node did not differ between the adequate and inadequate samples in the No-suction and $10 \mathrm{ml}$ suction group. However, in the $20 \mathrm{ml}$ suction subgroup, the mean node size in the adequate samples was $14.1 \mathrm{~mm}$, which was significantly higher than the node size in inadequate samples $(10.8 \mathrm{~mm})$.

\section{Influence of lymph node characteristics on the diagnostic yield:}

The heterogeneous lymph nodes had a better diagnostic yield in the $20 \mathrm{ml}$ suction group. Similarly, in the No-suction and $20 \mathrm{ml}$, suction group, the mean size of the lymph node from which diagnostic samples were obtained was significantly higher than non-diagnostic nodes. The remaining lymph node characteristics did not influence the diagnostic yield in any of the three suction groups.

\section{Complications:}

The proportion of EBUS-TBNA aspirates which were predominantly blood was similar in the three suction groups (No-suction:10.9\%, $10 \mathrm{ml}: 13.8 \%, 20 \mathrm{ml}$ : 15.4\%; $\mathrm{p}=0.62$ )

\section{Discussion}


The results of the present study indicate that EBUS-TBNA performed with No-suction or $10 \mathrm{ml}$ suction is non-inferior to $20 \mathrm{ml}$ suction pressure for sample adequacy. The amount of suction did not influence the diagnostic yield. Traditionally, most operators have used negative vacuum suction pressures in the hope of achieving good cellular material for cytology. However, this is based mostly on individual experiences and extrapolation from the technique of conventional TBNA, where negative suction is advocated.(14)

Our results show that overall specimen adequacy of EBUS-TBNA aspirates using "No-suction" was higher than that obtained by $10 \mathrm{ml}$ suction and $20 \mathrm{ml}$ suction ( $90 \%, 83.49 \%$, and $77.88 \%$ respectively). This indicates that EBUS-TBNA without suction provides the highest proportion of adequate samples for cytopathological analysis. As per our results, both No-suction and $10 \mathrm{ml}$ suction are non-inferior to $20 \mathrm{ml}$ of suction pressure in terms of sample adequacy. Furthermore, we found that the no-suction technique was actually superior to $20 \mathrm{ml}$ suction at a superiority margin of $3.92 \%$. Also, within the subgroups of sarcoidosis, tuberculosis, and lung cancer, adequacy of EBUS-TBNA aspirates obtained by each of the three suction pressures was similar.

Comparisons between different suction pressures for obtaining samples while performing EBUS have been sparsely reported. The study by Casal et al(7) compared the concordance between No-suction and $10 \mathrm{ml}$ suction during EBUS-TBNA and found no significant difference between the adequacy ( $88 \% \mathrm{vs}$. $88 \%)$ or quality of samples. Their study design differed from ours in that they applied each of the two suction pressures on the same lymph node. Similarly, two other authors have also reported similar specimen adequacy using $20 \mathrm{ml}$ suction or without suction. $(1,2)$ The adequacy obtained in these studies was higher than that obtained in our study. However, in one of those studies, the authors performed fourneedle punctures per node and applied both suction pressures in the same node for two passes each. It is possible that puncturing the node using one suction pressure could have altered the nodal architecture and influenced the yield of the suction pressure applied subsequently. Keeping these limitations in view, this study was designed to obtain a sample from each lymph node with a randomly assigned suction pressure only.

On the other hand, few studies have reported better yields with higher suction pressure. Boonsarngsuk et al(8) compared $0 \mathrm{ml}, 20 \mathrm{ml}$, and $40 \mathrm{ml}$ suction pressure in EBUS-TBNA and found no difference in the adequacy and diagnostic yield between $20 \mathrm{ml}$ and $40 \mathrm{ml}$ suction pressure; both of these, however, were superior to the results obtained by zero suction. Although this was the only study to compare three different suction pressures, it enrolled only 66 patients in whom one pass was performed using each of the three pressures. Thus, the possibility of the first-pass effect may have influenced the results. Furthermore, it must be kept in mind that the Vaclok syringe provided with the EBUS scope has a maximum capacity of $20 \mathrm{ml}$ suction. The study mentioned above used a customized syringe to apply 40 $\mathrm{ml}$ suction; this may compromise the uniformity of study methodology and add to the cost and logistic difficulties in real-world setting.

The overall diagnostic yield of EBUS-TBNA in our study was similar in each of the suction groups (Nosuction: $63.6 \%, 10 \mathrm{ml}: 52.3 \%$ and $20 \mathrm{ml}: 57.7 \%$; $=$ not significant). Subgroup analysis revealed that the 
diagnostic yield was highest in lung cancer in all the three suction categories compared to TB and sarcoidosis, although no statistical difference was observed. The overall diagnostic yield was relatively low compared to several previous reports, but comparable to that reported in the large AQuIRE registry.(4) Several reasons may explain this finding. Firstly, we calculated the yield based on the cytological results of the first three passes with either of the three suction pressures. The results of additional passes, if obtained, were not included in the final analysis. Secondly, only the findings of cytological smears were taken into account while calculating the diagnostic yield. The results from other investigations such as clot core biopsy, cell blocks, and GeneXpert were not considered since they are not done at our center as a routine protocol. It has been reported that GeneXpert may provide additive value in EBUS-TBNA for the diagnosis of Tuberculosis.(15)

However, the diagnostic yield of our study was better than previous studies for the same hypothesis. Casal et al(7) found a diagnostic yield of $36 \%$ and $34 \%$ in the $10 \mathrm{ml}$ suction and No-suction group, respectively; in malignant disorders, the yield was still lower, i.e., $28 \%$ and $26 \%$ respectively. Lin et al(2) compared use of suction vs. no-suction and stylet vs. no stylet and reported a diagnostic yield of $32.2 \%$ ( suction-stylet), 31.8\% (suction-no stylet), and 31\% (stylet-no-suction). Various registries on the diagnostic yield of EBUS-TBNA suggest a wide variation, possibly due to lack of stringent and uniform definition of this pathological outcome.(4) In fact, some authors have loosely defined diagnostic yield simply as "the presence of lymphocytes or any specific diagnosis".(4) In addition, most studies on EBUS emerge from Western countries, where malignancy constitutes a disproportionately high component of all procedures. In contrast, the majority of our subjects had a benign disease; this may be an important determinant of sample adequacy or diagnostic yield. The AQuIRE Bronchoscopy Registry (2011) reports unadjusted diagnostic yields of $37 \%$ to $54 \%$ for different hospitals.(4) A recent Indian study reported a diagnostic yield of $63 \%$ among 1582 patients, with a mean of two nodes being sampled.(16) It is known that several factors affect the diagnostic yield of EBUS, such as nodal size, number of needle punctures per node, nature of sedation or anesthesia, and the size of the needle used. $(3,5,6,17)$ On the other hand, diagnostic yield as low as $27 \%$ has also been reported, probably reflecting a real-world medical scenario wherein negative results are high in the absence of a robust and easily available diagnostic gold standard.(18) Recently, it has been postulated that ultrasonographic characteristics of lymph nodes influence the adequacy and diagnostic yield of EBUS aspirates. $(9,19)$ In a retrospective analysis, it was observed that the presence of well-defined margins, central hilar structure, and nodal conglomeration are independent predictors of benign etiology.(20) In our study, all lymph node characteristics were comparable in the three suction groups, except for the fact that nodes yielding adequate samples were larger, and diagnostic yield was better in the heterogeneous nodes in the $20 \mathrm{ml}$ suction group. Similarly, in the no-suction group, nodes that were diagnostic were larger than non-diagnostic nodes. None of the other nodal characteristics influenced the adequacy or diagnostic yield between the three suction pressure groups.

Bleeding, albeit mild, is one of the commonest complications of EBUS-TBNA, followed by other less common events such as arrhythmias, hypotension, and respiratory failure.(21) One of the hypotheses of the current study was that the use of negative suction might lead to bloody aspirates, thereby qualifying 
as inadequate and non-diagnostic specimens. This was proven correct because $15.4 \%$ of aspirates obtained by $20 \mathrm{ml}$ suction were predominantly blood, compared to $10.9 \%$ and $13.8 \%$ bloody samples using no-suction and $10 \mathrm{ml}$ suction respectively, although this difference was not statistically significant. Similarly, previous studies that analyzed the proportion of bloody samples obtained with and without suction have not found any difference. $(7,22)$ On the other hand, using endoscopic ultrasound-guided fine needle aspiration (EUS-FNA), Wallace et al(23) found that the odds of obtaining a bloody aspirate was 4.7 times higher when suction was used compared to without suction. We opine that similar inferences may be drawn for EBUS-TBNA, a procedure that technically resembles EUS.

To our knowledge, this randomized trial is the largest yet to assess the utility of negative suction during EBUS-TBNA. The fact that we used only one of the three suction pressures per node helped to negate the potential bias likely due to the "first-pass effect." This, along with the "blinding" of the cytopathologist, helped control for the confounding effects of various lymph node characteristics on the outcome parameters. Also, the present study had a mix of patients with mediastinal lymphadenopathy due to both benign and malignant diseases, more closely reflecting a real-life clinical scenario and thus making the results more generalizable.

There are some limitations to this study as well. Firstly, we did not routinely use cell-block or tissue core for the processing of samples. Secondly, Gene Xpert and liquid cultures for TB were not done separately for aspirates obtained with each of the three suction pressures and hence were not used for calculating the study outcomes. Thirdly, the procedures were performed by different operators with varying levels of experience in EBUS, although this possibly makes our results more generalizable. Despite these shortcomings, we feel that this study adds useful information to the technique of EBUS-TBNA and has potential practice changing implications.

\section{Conclusion}

The results of our prospective randomized trial show that EBUS-TBNA performed with or without the application of negative suction does not influence the adequacy and diagnostic yield of the aspirates. "No-suction" is superior to $20 \mathrm{ml}$ suction pressure in terms of adequacy of EBUS-TBNA aspirates and is associated with a lesser risk of bloody specimens.

\section{Declarations}

Disclosure statement: None of the co-authors have any conflicts of interest or financial disclosures related to this manuscript.

\section{References}

1. Harris K, Maroun R, Attwood K, Chalhoub M. Comparison of cytologic accuracy of endobronchial ultrasound transbronchial needle aspiration using needle suction versus no suction. Endoscopic 
ultrasound. 2015;4(2):115-9.

2. Lin X, Ye M, Li Y, Ren J, Lou Q, Li Y, et al. Randomized controlled trial to evaluate the utility of suction and inner-stylet of EBUS-TBNA for mediastinal and hilar lymphadenopathy. BMC pulmonary medicine. 2018;18(1):192.

3. Mohan A, Naik S, Pandey RM, Mills J, Munavvar M. Diagnostic utility of endobronchial ultrasound guided transbronchial needle aspiration for mediastinal lesions: A prospective three year, single centre analysis. Thoracic cancer. 2011;2(4):183-9.

4. Ost DE, Ernst A, Lei X, Feller-Kopman D, Eapen GA, Kovitz KL, et al. Diagnostic yield of endobronchial ultrasound-guided transbronchial needle aspiration: results of the AQuIRE Bronchoscopy Registry. Chest. 2011;140(6):1557-66.

5. Chaddha U, Ronaghi R, Elatre W, Chang CF, Mahdavi R. Comparison of Sample Adequacy and Diagnostic Yield of 19- and 22-G EBUS-TBNA Needles. Journal of bronchology \& interventional pulmonology. 2018;25(4):264-8.

6. Oki M, Saka H, Ando M, Nakashima H, Shiraki A, Murakami Y, et al. How Many Passes Are Needed for Endobronchial Ultrasound-Guided Transbronchial Needle Aspiration for Sarcoidosis? A Prospective Multicenter Study. Respiration; international review of thoracic diseases. 2018;95(4):251-7.

7. Casal RF, Staerkel GA, Ost D, Almeida FA, Uzbeck MH, Eapen GA, et al. Randomized clinical trial of endobronchial ultrasound needle biopsy with and without aspiration. Chest. 2012;142(3):568-73.

8. Boonsarngsuk V, Pongtippan A, Juthakarn S. The effect of aspiration pressure over endobronchial ultrasound-guided transbronchial needle aspiration on the diagnosis of intrathoracic lymphadenopathies. Lung. 2013;191(4):435-40.

9. Wahidi MM, Herth F, Yasufuku K, Shepherd RW, Yarmus L, Chawla M, et al. Technical Aspects of Endobronchial Ultrasound-Guided Transbronchial Needle Aspiration: CHEST Guideline and Expert Panel Report. Chest. 2016;149(3):816-35.

10. Dhamija A, Ganga VB, Guliani A, Raveendran R, Verma K, Basu AK. Endobronchial ultrasound for tubercular mediastinal adenopathy and its comparison with traditional tools. The international journal of tuberculosis and lung disease : the official journal of the International Union against Tuberculosis and Lung Disease. 2019;23(8):907-12.

11. Schulz KF, Altman DG, Moher D, Group C. CONSORT 2010 statement: updated guidelines for reporting parallel group randomised trials. BMJ. 2010;340:c332.

12. Jain D, Allen TC, Aisner DL, Beasley MB, Cagle PT, Capelozzi VL, et al. Rapid On-Site Evaluation of Endobronchial Ultrasound-Guided Transbronchial Needle Aspirations for the Diagnosis of Lung Cancer: A Perspective From Members of the Pulmonary Pathology Society. Archives of pathology \& laboratory medicine. 2018;142(2):253-62.

13. Products CfPM. Points to consider on switching between superiority and non-inferiority. Br J Clin Pharmacol. 2001;52(3):223-8. 
14. Mehta AC, Wang KP. Teaching conventional transbronchial needle aspiration. A continuum. Annals of the American Thoracic Society. 2013;10(6):685-9.

15. Dhasmana DJ, Ross C, Bradley CJ, Connell DW, George PM, Singanayagam A, et al. Performance of Xpert MTB/RIF in the diagnosis of tuberculous mediastinal lymphadenopathy by endobronchial ultrasound. Annals of the American Thoracic Society. 2014;11(3):392-6.

16. Prasad KT, Dhooria S, Sehgal IS, Muthu V, Ram B, Gupta N, et al. Endobronchial ultrasound-guided transbronchial needle aspiration in the economically disadvantaged: A retrospective analysis of 1582 individuals. Lung India : official organ of Indian Chest Society. 2018;35(6):483-7.

17. Cornelissen CG, Dapper J, Dreher M, Muller T. Endobronchial ultrasound-guided transbronchial needle aspiration under general anesthesia versus bronchoscopist-directed deep sedation: A retrospective analysis. Endoscopic ultrasound. 2019;8(3):204-8.

18. Lange TJ, Kunzendorf F, Pfeifer M, Arzt M, Schulz C. Endobronchial ultrasound-guided transbronchial needle aspiration in routine care - plenty of benign results and follow-up tests. International journal of clinical practice. 2012;66(5):438-45.

19. Fujiwara T, Yasufuku K, Nakajima T, Chiyo M, Yoshida S, Suzuki M, et al. The utility of sonographic features during endobronchial ultrasound-guided transbronchial needle aspiration for lymph node staging in patients with lung cancer: a standard endobronchial ultrasound image classification system. Chest. 2010;138(3):641-7.

20. Ayub, II, Mohan A, Madan K, Hadda V, Jain D, Khilnani GC, et al. Identification of specific EBUS sonographic characteristics for predicting benign mediastinal lymph nodes. The clinical respiratory journal. 2018;12(2):681-90.

21. Dhooria S, Sehgal IS, Gupta N, Aggarwal AN, Behera D, Agarwal R. Diagnostic Yield and Complications of EBUS-TBNA Performed Under Bronchoscopist-directed Conscious Sedation: Single Center Experience of 1004 Subjects. Journal of bronchology \& interventional pulmonology. 2017;24(1):7-14.

22. Lin SM, Chung FT, Huang CD, Liu WT, Kuo CH, Wang $\mathrm{CH}$, et al. Diagnostic value of endobronchial ultrasonography for pulmonary tuberculosis. J Thorac Cardiovasc Surg. 2009;138(1):179-84.

23. Wallace MB, Kennedy T, Durkalski V, Eloubeidi MA, Etamad R, Matsuda K, et al. Randomized controlled trial of EUS-guided fine needle aspiration techniques for the detection of malignant lymphadenopathy. Gastrointestinal endoscopy. 2001;54(4):441-7.

\section{Tables}

\section{Table 1: Baseline characteristics of study patients}




\begin{tabular}{|ll|}
\hline Characteristic & Value \\
\hline Total No. of patients & 325 \\
\hline Gender & \\
\hline Male & $195(60)$ \\
Female & $130(40)$ \\
\hline Age (years) & $46.9 \pm 15.8$ \\
\hline Indication of EBUS & \\
\hline Diagnostic & 306 \\
\hline Staging & 18 \\
\hline Both & 1 \\
\hline Total Number of lymph nodes sampled & 323 \\
\hline Lymph node size (mm) & $13.8 \pm 6.1$ \\
\hline Lymph node stations sampled & \\
\hline Right paratracheal (4R) & $133(41.2)$ \\
\hline Subcarinal (7) & $110(34)$ \\
\hline Left interlobar (11L) & $28(8.7)$ \\
\hline Left paratracheal (4L) & $21(6.5)$ \\
\hline Right interlobar (11R) & $19(5.9)$ \\
\hline Right Hilar (10R) & $10(3.1)$ \\
\hline Left upper paratracheal (2L) & $1(0.3)$ \\
\hline III-defined mass & $1(0.3)$ \\
\hline
\end{tabular}

Data presented as Number (\%) or mean \pm SD

Table 2: Characteristics of all patients in the three suction groups: 


\begin{tabular}{|lclll|}
\hline Variable & No-suction & $\mathbf{1 0 ~} \mathbf{~ m l ~ s u c t i o n}$ & $\mathbf{2 0 ~} \mathrm{ml}$ suction & p-value \\
\hline Gender & & & & \\
\hline Male & $74(66.7)$ & $65(59.6)$ & $56(53.3)$ & 0.14 \\
\hline Female & $37(33.3)$ & $44(40.4)$ & $49(46.7)$ & \\
\hline Age (years) & $46.4(15.2)$ & $46.6(17.0)$ & $47.7(15.2)$ & 0.81 \\
\hline Size (mm) & $13.8(6.3)$ & $14.1(6)$ & $13.4(6.2)$ & 0.68 \\
\hline Lymph node station sampled & & & \\
\hline Right paratracheal & $48(43.7)$ & $37(33.9)$ & $48(46.2)$ & \\
\hline Subcarinal & $37(33.6)$ & $44(40.4)$ & $29(27.9)$ & \\
\hline Others & $25(22.7)$ & $28(25.7)$ & $27(25.9)$ & \\
\hline
\end{tabular}

Data presented as Number (\%)

Table 3: Characteristics of lymph nodes in the three suction groups 


\begin{tabular}{|c|c|c|c|c|}
\hline Characteristic & $\begin{array}{l}\text { No-suction } \\
(n=110)\end{array}$ & $\begin{array}{l}10 \mathrm{ml} \text { suction } \\
(\mathrm{n}=109)\end{array}$ & $\begin{array}{l}20 \mathrm{ml} \text { suction } \\
(\mathrm{n}=104)\end{array}$ & p-value \\
\hline \multicolumn{5}{|l|}{ Echogenicity } \\
\hline Homogeneous & $77(70)$ & $76(69.7)$ & $76(73.1)$ & \multirow[t]{2}{*}{0.84} \\
\hline Heterogeneous & $33(30)$ & $33(30.3)$ & $28(26.9)$ & \\
\hline \multicolumn{5}{|l|}{ Calcification } \\
\hline Present & $7(6.4)$ & $3(2.8)$ & $3(2.9)$ & \multirow[t]{2}{*}{0.41} \\
\hline Absent & 103 (93.6) & $106(97.2)$ & $101(97.1)$ & \\
\hline \multicolumn{5}{|c|}{ Coagulation necrosis } \\
\hline Present & $15(13.6)$ & $12(11)$ & $10(9.6)$ & \multirow[t]{2}{*}{0.64} \\
\hline Absent & $95(86.4)$ & $97(89)$ & $94(90.4)$ & \\
\hline \multicolumn{5}{|c|}{ Central Hilar structure } \\
\hline Present & $7(6.4)$ & $7(6.4)$ & $4(3.8)$ & \multirow[t]{2}{*}{0.69} \\
\hline Absent & $103(93.6)$ & $102(93.6)$ & $100(96.2)$ & \\
\hline \multicolumn{5}{|c|}{ Intranodal vessels } \\
\hline Present & $6(5.5)$ & $8(7.3)$ & $7(6.7)$ & \multirow[t]{2}{*}{0.85} \\
\hline Absent & $104(94.5)$ & $101(92.7)$ & 97 (93.3) & \\
\hline \multicolumn{5}{|l|}{ Margins } \\
\hline Discrete & 107 (97.3) & $107(98.2)$ & $100(96.2)$ & \multirow[t]{2}{*}{0.65} \\
\hline III defined & $3(2.7)$ & $2(1.8)$ & $4(3.8)$ & \\
\hline \multicolumn{5}{|l|}{ Consistency } \\
\hline Firm & 105 (95.5) & 106 (97.3) & $101(97.1)$ & \multirow[t]{3}{*}{0.59} \\
\hline Soft & $1(0.9)$ & $2(1.8)$ & $2(1.9)$ & \\
\hline Hard & $4(3.6)$ & $1(0.9)$ & $1(1)$ & \\
\hline Node size $(\mathrm{mm})$ & $13.8 \pm 6.3$ & $14.1 \pm 6$ & $13.4 \pm 6.2$ & 0.68 \\
\hline
\end{tabular}

All values expressed as number (\%) or mean \pm SD 


\begin{tabular}{|lllll|}
\hline Specimen Adequacy & No-suction $(\mathrm{n}=\mathbf{8 1})$ & $\mathbf{1 0} \mathrm{ml}$ suction $(\mathrm{n}=\mathbf{6 8})$ & $\mathbf{2 0 ~ m l ~ s u c t i o n}$ & p-value \\
& & & & \\
& & & $(\mathrm{n}=70)$ & \\
\hline Sarcoidosis & $37 / 39(94.9)$ & $28 / 30(93.3)$ & $27 / 31(87.1)$ & 0.53 \\
$(\mathrm{n}=100)$ & $\{82.7-99.4\}$ & $\{77.9-99.2\}$ & $\{70.2-96.4\}$ & \\
\hline Tuberculosis & $23 / 25(92)$ & $23 / 27(85.2)$ & $19 / 26(73.1)$ & 0.18 \\
$(\mathrm{n}=78)$ & $\{73.9-99\}$ & $\{66.3-95.8\}$ & $\{52.2-88.4\}$ & \\
Ca-Lung & $17 / 17(100)$ & $9 / 11(81.8)$ & $11 / 13(84.6)$ & 0.16 \\
$(\mathrm{n}=41)$ & $\{80.5-100\}$ & $\{48.2-97.7\}$ & $\{54.6-98.1\}$ & \\
\hline
\end{tabular}

Data presented as Number (\%) and $\{95 \%$ Confidence interval\}

Table 5: Diagnostic yield in the three suction pressure groups

\begin{tabular}{|lllll|}
\hline Diagnostic yield & $\begin{array}{l}\text { No-suction } \\
(\mathbf{n}=191)\end{array}$ & $\begin{array}{l}10 \mathrm{ml} \text { suction } \\
(\mathrm{n}=177)\end{array}$ & $\begin{array}{l}\mathbf{2 0} \mathrm{ml} \text { suction } \\
(\mathbf{n}=174)\end{array}$ & p-value \\
\hline Overall & $70 / 110(63.6)$ & $57 / 109(52.3)$ & $60 / 104(57.7)$ & 0.24 \\
$(\mathrm{n}=323)$ & $\{53.9-72.6\}$ & $\{42.5-61.9\}$ & $\{47.6-67.3\}$ & \\
\hline Sarcoidosis & $29 / 39(74.4)$ & $19 / 30(63.3)$ & $21 / 31(67.7)$ & 0.61 \\
$(\mathrm{n}=100)$ & $\{57.9-86.9\}$ & $\{43.9-80.1\}$ & $\{48.6-83.3\}$ & \\
\hline Tuberculosis & $19 / 25(76)$ & $17 / 27(62.9)$ & $15 / 26(57.7)$ & 0.37 \\
$(\mathrm{n}=78)$ & $\{54.9-90.6\}$ & $\{42.4-80.6\}$ & $\{36.9-76.6\}$ & \\
\hline Ca-Lung & $13 / 17(76.5)$ & $8 / 11(72.7)$ & $10 / 13(76.9)$ & 0.9 \\
$(\mathrm{n}=41)$ & $(50.1-93.2)$ & $(39-93.9)$ & $(46.2-94.9)$ & \\
\hline
\end{tabular}

Data presented as Number (\%) and $\{95 \%$ Confidence interval $\}$ 
Figures

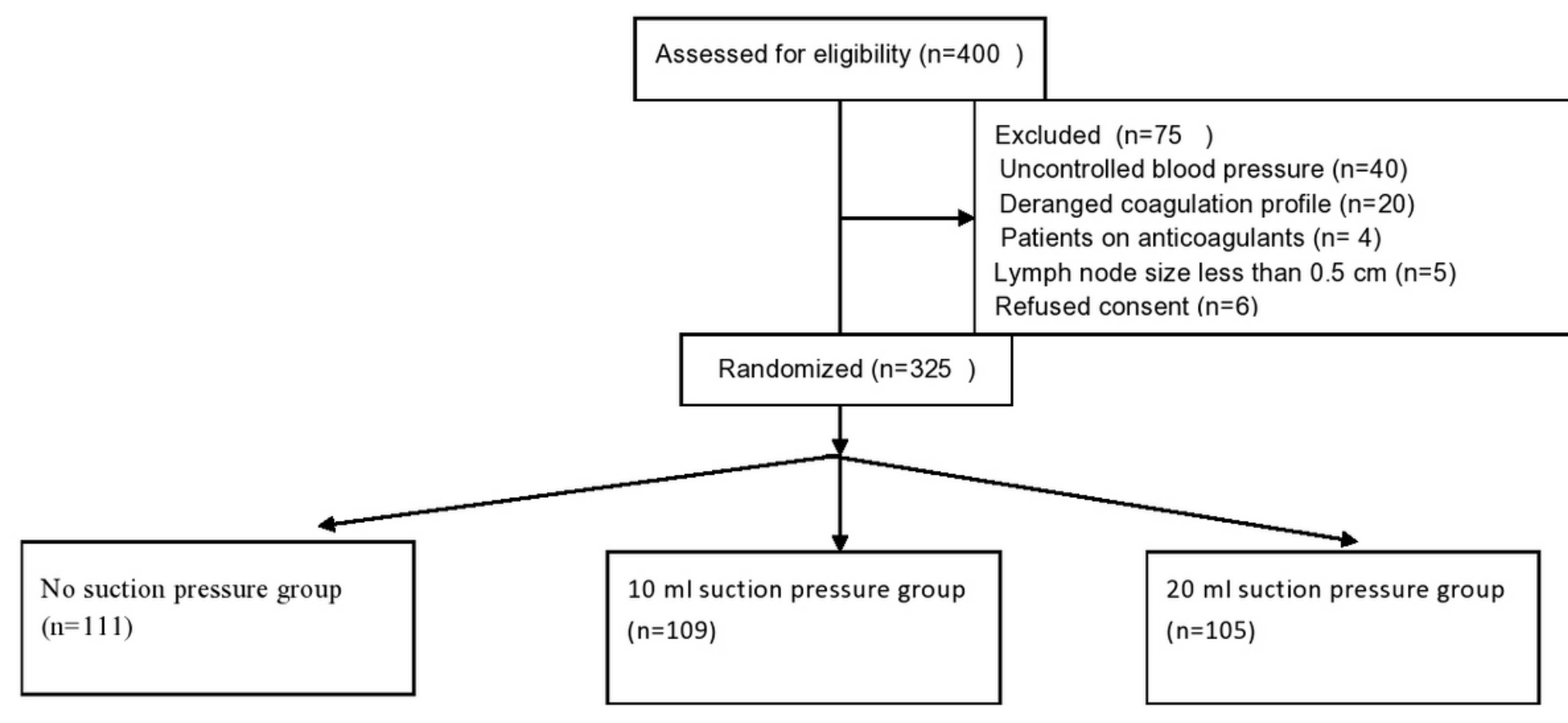

\section{Figure 1}

Process of subject recruitment and evaluation 


\section{ES (95\% Cl)}

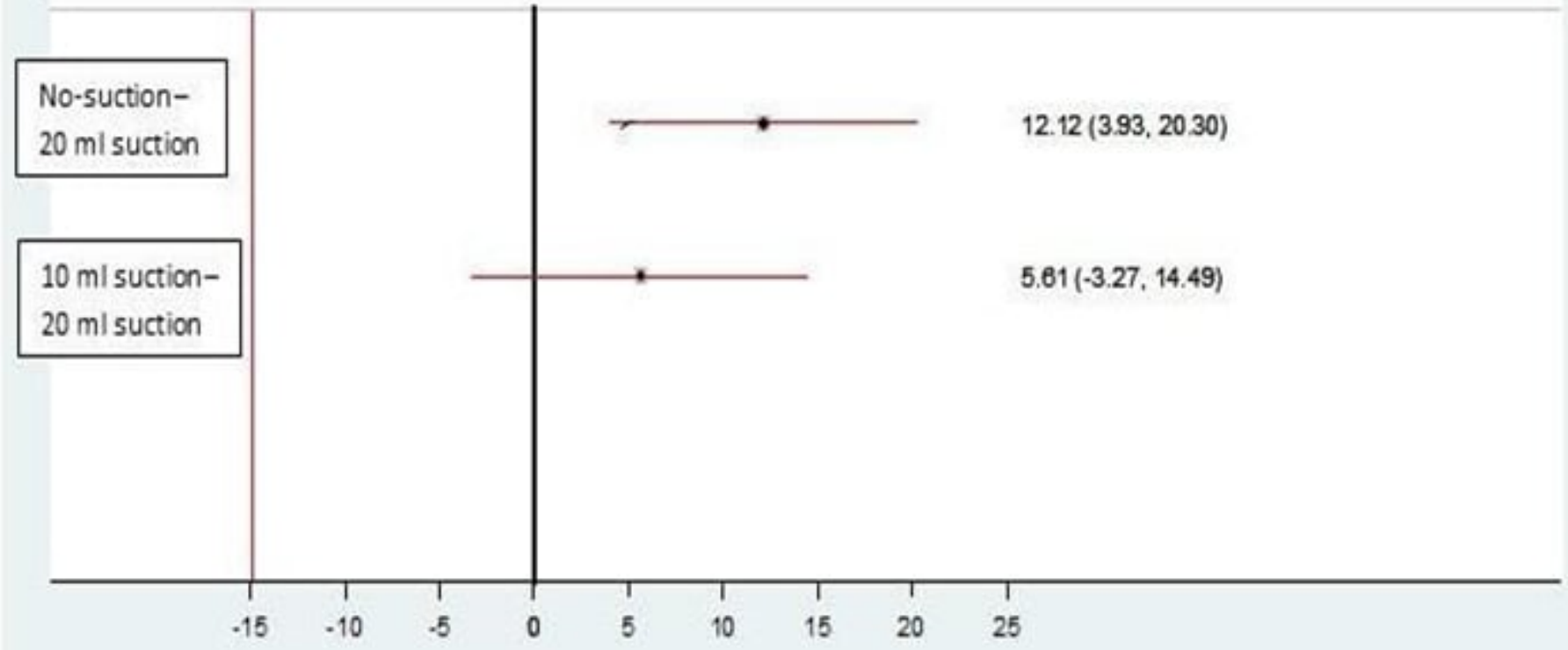

Figure 2

Difference in sample adequacy between "No-suction" and $20 \mathrm{ml}$ suction, and between $10 \mathrm{ml}$ and $20 \mathrm{ml}$ suction pressure 